\title{
Blood Lymphocyte Morphology: It Depends on How Blood Smears are Dried
}

\author{
Kazuo Oshimi* \\ Ex-Professor of Department of Hematology, Juntendo University School of Medicine, Japan
}

Received: January 30, 2018; Published: February 12, 2018

*Corresponding author: Kazuo Oshimi, Department of Hematology, Juntendo University School of Medicine, and Kushiro Central Hospital, Japan, Tel: 010-81-154-64-7277; Email: kazuoshimi@gmail.com

Keywords: How to dry blood smears; Natural-air drying; Forced air drying; Hairy cell leukemia; LGL leukemia

Abbreviations: HCL: Hairy Cell Leukemia; LGL: Large Granular Lymphocytes; LGLL: Large Granular Lymphocyte Leukemia; T-LGLL: T Cell Large Granular Lymphocyte Leukemia; NK: Natural Killer; FAB: French American British; RBC: Red Blood Cells

\section{Introduction}

When I was young, I was wondering why the size of chronic lymphocytic leukemia cells described in Western countries is always smaller than that of our Japanese patients. Do we have a different disease? But, I found later that this difference is caused by the methods how blood smears are dried [1].

\section{How to dry blood smears?}

After blood smears are made on microscope slides, they are left and dried naturally without using a fan before staining (natural-air drying), or they are dried immediately in an airstream by blowing air onto the smears (forced-air drying). As far as I know, in most or many hospitals in Western countries, they use the natural-air drying method, although the forced-air drying method is sometimes recommended in the English literature. In all the hospitals in Japan, blood smears are dried immediately by a fan. Natural-air drying is not done routinely. The natural-air drying method causes the smears to dry slowly, and cells shrink, particularly when there is high humidity. But, I cannot find any articles to describe how cells shrink on different humidity or on different temperature.

According to many pictures presented from Western countries, it is sometimes difficult to see fine intracellular structures on naturally dried smears. The forced-air drying method, on the other hand, causes the smears to dry more rapidly, and cells shrink less. It is then easier to see fine intracellular structures. However, it is difficult to see hair-like surface projections on hairy cells by forced-air drying, making the diagnosis of hairy cell leukemia (HCL) difficult. By photos, I will show a morphological difference in HCL cells made by these two methods, and discuss advantages and disadvantages of these methods.
Example 1: HCL- HCL is characterized by the cells having hairlike surface projections along the cellular outlines. Five different types of HCL have been described (2), and they differ clinically, morphologically, phenotypically, and/or genetically. Fig. 1 shows HCL cells of a patient, who was diagnosed to have splenic diffuse red pulp small B-cell lymphoma by splenectomy. The blood smear made by forced-air drying (Figure 1A) showed a large agranular lymphocyte, or sunny-side up lymphocyte, with broad agranular cytoplasm and unclear hair-like projections. A smear naturally dried (Figure 1B) showed a smaller-sized cell with clear hairy projections on the cell surface, characteristic of HCL. If we did not make a naturally dried smear, we could not make the diagnosis of HCL, because it is usually difficult to see hair-like projections on the slides made by forced-air drying, except for on the head of the smear, where the cells are dense and dry slowly.

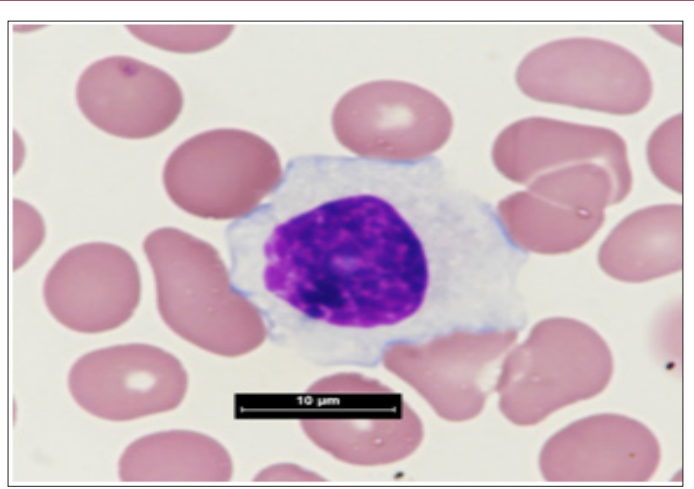

Figure 1A: Peripheral blood smears of a patient with splenic diffuse red pulp small B-cell lymphoma. In this a blood smear was made by forced-air drying. 


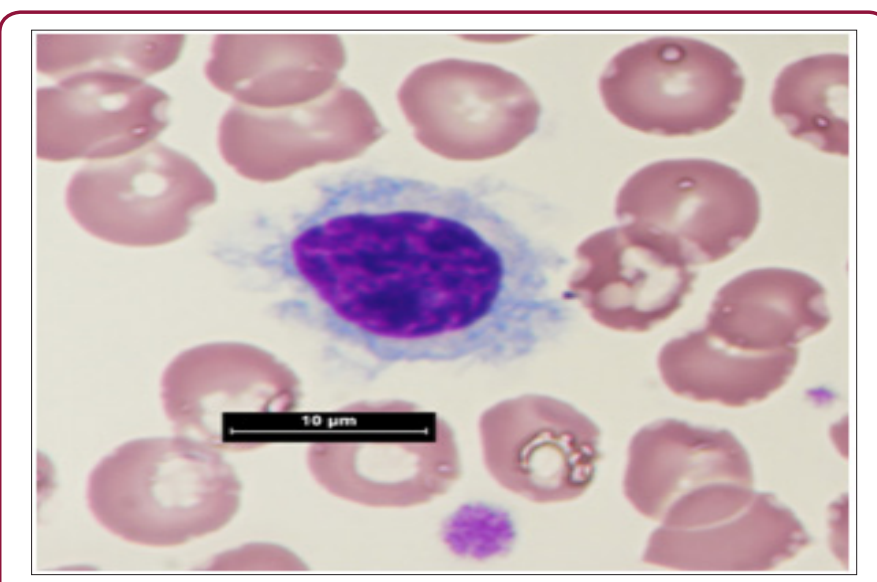

Figure 1B: By Natural Drying.

Until about 20 years ago, I did not know that hair-like projections do appear when naturally dried smears are made, but not when forced-air dried slides are made. A unique, noteworthy variant of HCL, called HCL Japanese variant, was proposed some 30 years ago by Japanese investigators, but hair-like projections were not found in blood smears of their article (3), probably because blood smears were made by forced-air drying. When large lymphocytes lacking azurophilic granules in the cytoplasm are found on the smears made by forced-air drying, I strongly recommend making naturally dried smears in addition to make forced-air dried smears in Japan. The incidence of HCL is lower in Japan than in Western countries, and this may be partly explained by the method to prepare blood smears.

Example 2: large granular lymphocyte leukemia (LGLL): Large granular lymphocytes (LGL) are large lymphocytes with azurophilic granules in their cytoplasm. Normal LGL are either NK cells or T cells, and LGLL includes three different disorders; T-cell LGLL (T-LGLL), chronic lymphoproliferative disorder of NK cells, and aggressive NK-cell leukemia. T-LGLL is most common, and exhibits indolent clinical course (4). I want to focus whether normal LGL and T-LGLL cells are really large in size. What is the definition of large lymphocytes? The definition differs remarkably among investigators. The FAB classification defines B lymphocytes large when they are more than twice the size of RBC (5). Others define lymphocytes large simply by cell diameter $(6,7)$. When the definition of FAB classification is applied to T-LGLL cells obtained from our eight patients, they were not large when blood smears were made by forced-air drying. When smears were made by natural-air drying in our three patients and three normal individuals, the size of RBC did not change significantly, but that of T-LGLL cells and normal LGL became smaller than the smears made by forced-air dying Accordingly, the ratio of T-LGLL cells to RBC became further lower (manuscript, in preparation).

\section{Advantages and Disadvantages of Natural-Air Drying Method and Forced-Air Drying Method.}

As stated already, there are two drying methods, each having advantages and disadvantages. Judging from the fact that hair-like projections are visible by natural-air drying in Western countries, cell shrinkage also happens in Western countries by natural-air drying, and it will be possible to see fine intracellular structures by forced-air drying. Thus I believe it is much better to use forcedair drying method in Western countries as well, in order to see the structures of lymphocytes as well as other types of leukocytes. This will also be true for bone marrow cells. In Japan, a machine for automatically preparing and staining blood smears is available. This machine is equipped with a small fan inside. This machine is being used allover in Japan, and we usually see the blood smears made by this machine. In hospitals having a small number of patients, blood smears are dried manually by a fan such as a hair dryer. When this automatic machine is exported abroad, I heard that the fan switch is turned off beforehand. In anyway, our routine procedure to make smears in Japan is forced-air drying. I recommend in Japan to use natural-air drying in addition to forced-air drying, particularly when patients are suspected to have lympho proliferative disorders (1). In Western countries, why don't you use forced-air drying routinely to see fine intracellular structures to get closer to the correct diagnosis?

\section{Conclusion}

In Western countries, it will be recommended to use forcedair drying to make blood smears, or at least two drying methods be compared before you decide to use or not to use the forcedair drying method. This method is good to see fine intracellular structures, but it has a big disadvantage of being difficult to find HCL cells, this seeming to be the only one disadvantage, as far as I know, except for that you have to use a fan. When you start to use the forced-air drying method, normal lymphocytes may look atypical, but you will be able to differentiate them, when you get used to it. After understanding its disadvantages, please use the forced-air drying method.

\section{Acknowledgment}

I thank Ms. Yukika Yamada, Miyoko Miura, and Mayu Tagari of Kushiro Central Hospital for their making blood smears, taking photos, and measuring the diameter of lymphocytes. This review article is dedicated to the late Dr. Keizo Kajiwara, who supported and encouraged us.

\section{References}

1. Isobe Y, Tomomatsu J, Tsukune Y, Tsukada N, Sasaki M, et al. (2012) Diagnostic problems among chronic lymphocytic leukemia and other indolent B cell leukemias in a Japanese population. Intern Med 51(15): 1977-1981.

2. Traverse Glehen A, Baseggio L, Salles G, Coiffier B, Felman P, et al. (2012) Splenic diffuse red pulp small B cell lymphoma Toward the emergence of a new lymphoma entity. Discov Med 13(71): 253-265.

3. Machii T, Tokumine Y, Inoue R, Kitani T (1993) Predominance of a distinct subtype of hairy cell leukemia in Japan. Leukemia 7(2): 181-186.

4. Oshimi K (2017) Clinical features pathogenesis and treatment of large granular lymphocyte leukemias. Intern Med 56(14): 1759-1769.

5. Bennett JM, Catovsky D, Daniel MT, Flandrin G, Galton DA, et al. (1989) Proposals for the classification of chronic (mature) B and T lymphoid leukemia. French American British (FAB) co operative group. J Clin Pathol 42(6): 567-584. 
6. Baird SM (2006) Morphology of lymphocytes and plasma cells. Williams Hematology $7^{\text {th }}$ edn. McGraw Hill, New York, USA.

CC (i) This work is licensed under Creative Submission Link: http://biomedres.us/submit-manuscript.php
7. Vajpayee N, Graham SS (2017) Basic examination of blood and bone marrow. Henrys Clinical Diagnosis and Management by Laboratory Methods 23rd ed. McPherson RA, Pincus MR, 10-539, Elsevier St Louis.

$\begin{array}{ll}\text { BIOMEDICAL } & \text { Assets of Publishing with us } \\ \text { RESEARCHES } & \text { - Global archiving of articles } \\ \text { - Immediate, unrestricted online access }\end{array}$

